\title{
EVALUATION OF THE 2-AXIS MOVEMENT OF A 5-AXIS GANTRY ROBOT FOR WELDING APPLICATIONS
}

\author{
Ario Sunar Baskoro ${ }^{1 *}$, Reggi Prasetyo Kurniawan ${ }^{1}$, Haikal $^{1}$ \\ ${ }^{1}$ Department of Mechanical Engineering, Faculty of Engineering, Universitas Indonesia, Kampus UI \\ Depok, Depok 16424, Indonesia
}

(Received: April 2018 / Revised: March 2019 / Accepted: May 2019)

\begin{abstract}
The development of technology in fabrication and manufacturing systems is increasing nowadays. The use of robots as mediators to assemble all kinds of product has become a new challenge in this era, and robotic welding technology is now the choice for certain automotive industries to produce their vehicle products. This research will develop an artificial robot welder with a type of gantry robot as a training prototype to gain more in-depth knowledge of industrial robots. The purpose of the paper is to develop an initial welding robot system, focusing on evaluation of the 2-axis movement of $\mathrm{X}$ and $\mathrm{Y}$. The robot's movement will be controlled by a microcontroller, and its level of accuracy and repeatability will be measured a by Faro Arm Portable Coordinate Measuring Machine (PCMM) with an error of around 0.02 $\mathrm{mm}$. This measurement method will consist of five speed characteristics, which make the robot move for a constant distance of $125 \mathrm{~mm}$. The results show that the best level of accuracy is $0.83 \%$, at $2.5 \mathrm{~mm} / \mathrm{s}$ of velocity. The $\mathrm{X}$ and $\mathrm{Y}$ axes produce movement with the best repeatability of $96 \mu \mathrm{m}$ and $108 \mu \mathrm{m}$, respectively. Based on the results, the gantry robot displays good performance in repeatability and accuracy, proving it can work effectively.
\end{abstract}

Keywords: Accuracy; Gantry robot; Repeatability; Welding application

\section{INTRODUCTION}

Many industries have recently used robotic assistance in their industrial processes, such as welding, tasting and stamping. In addition, the demand for robots in industry has also increased, in line with better levels of accuracy and repeatability (Nubiola \& Bonev, 2013). Many types of robots are used in industry, such as arm robots and gantry robots. The gantry robot is a robotics system that is widely used in industrial manufacturing processes, due to the larger workspace area that can be achieved and high levels of stiffness. Since 1998, such robots have used for precision manufacturing and materials handling in the electronics, nuclear and automotive industries (Baicu et al., 1998). Nowadays, they are not only used for materials handling, but also for welding applications such as arc and spot welding. The requirements for robots that are suitable for use in industry include at least good accuracy and repetition rates (Zaeh et al., 2010).

Welding is an important technique and is often used in industry to join metals quickly, strongly and economically. Robotic welding technology has been implemented in many industrial sectors to increase the level of production. In addition, using such technology can improve weld quality and the consistency of weld results, and reduce associated costs and product defects

\footnotetext{
*Corresponding author's email: ario@eng.ui.ac.id, Tel. +62-21-7270032, Fax. +62-21-7270033
}

Permalink/DOI: https://doi.org/10.14716/ijtech.v10i5.1865 
(Kah et al., 2015). Friction stir welding (FSW) is an advanced welding technology to join light materials used in gantry-type CNC system manufacturing processes in the aircraft, aerospace and automotive industries. Another process for welding similar light materials is to use aluminum to aluminum resistance spot welding (RSW) (Baskoro et al., 2017) and for dissimilar materials aluminum to steel RSW (Muzakki et al., 2018). Using FSW to join aluminum has several advantages compared to fusion welding and riveting processes (Baskoro et al., 2015).

The development of gantry robots has been researched for a considerable time; Ji-Hyoung et al. (2001), for example, developed a multi-axis gantry type welding robot system for automated fabrication of shipbuilding and steel bridge line subassemblies. It was reported that using a PCbased controller on the gantry robot was more compatible than a robot controller and that cost efficiency could be reduced. However, using a gantry robot as a robotic mechanical system faces certain problems, especially related to movement. Meressi (1998) created sliding mode and fuzzy scheduled linear controllers to minimize the rope angle oscillations of a threedimensional gantry robot during travel and transverse motion in reasonably high-speed maneuvers. Recently, many types of research approach have been undertaken to develop FSW welding tool technology from gantry type CNC systems with industrial robots (Von Strombeck et al., 2001; Smith, 2004; Soron \& Kalaykov, 2006; Mendes et al. 2016). Nevertheless, several problems have arisen because industrial robots have the limitation of only being able to join aluminum materials of up to $8 \mathrm{~mm}$ thickness (Voellner et al., 2008). Furthermore, high lateral force emerges during the FSW process, so a mechanism with high stiffness is needed (Guillo \& Dubourg, 2016).

The accuracy of robots is important if applied to an offline program, but if they are taught manually at the end-effector of the robot, the accuracy is not important. Several issues can cause errors in robot accuracy, such as ones linked to computation, measurement, application, the environment or parameters. Another important aspect of robots is their level of repeatability. In industry, robots used have a better repeatability rate than level of accuracy. The calibration method was one method to increase the level of robotic accuracy if the robot already had a good level of repeatability (Nubiola \& Bonev, 2013).

A gantry robot is more compatible than a jointed arm robot for FSW applications which need a high-performance machine. Previous studies by Guillo and Dubourg (2016) and Samhouri et al. (2005) have focused on the gantry robot, but have been limited to the 3-axis type. This paper develops a 5-axis gantry robot system for FSW welding applications, but this preliminary study will focus on evaluation of the 2-axis movement of $\mathrm{X}$ and $\mathrm{Y}$. One of the applications of this robot is that it can be used to make honeycomb structures (Cohal, 2017). Robot testing was conducted by its movement, which measured the suitability of the repeatability and accuracy of the target.

\section{EXPERIMENTAL METHODS}

The schematic of the gantry robot system with a 2D robot movement of the $\mathrm{X}$ axis and $\mathrm{Y}$ axis is shown in Figure 1. Figures 1a and $1 \mathrm{~b}$ show the schematic and a photograph of the gantry robot system respectively. The magnitude of the large displacement of the robot was measured by a Faro Arm Portable Coordinate Measuring Machine (PCMM) with measurement accuracy of $0.02 \mathrm{~mm}$. 


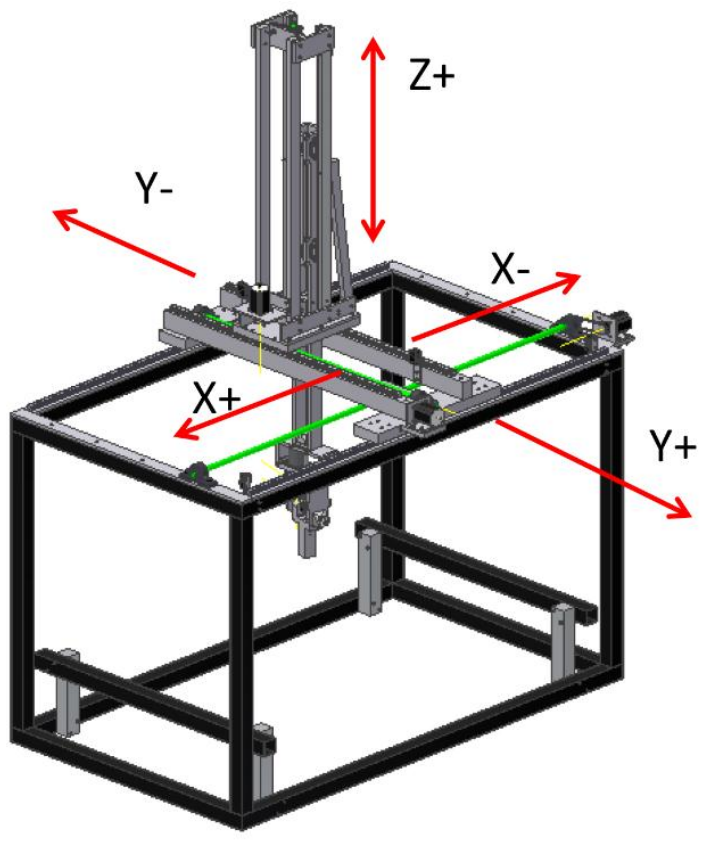

(a)

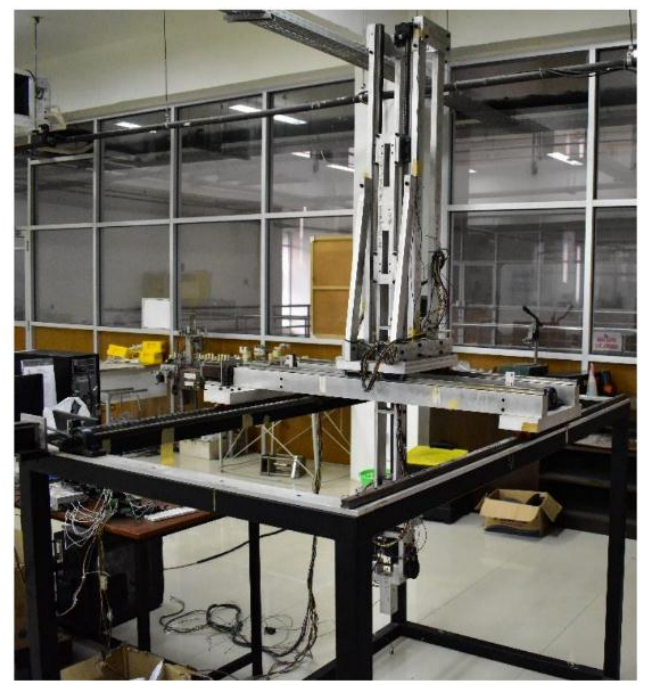

(b)

Figure 1 Gantry robot system: (a) schematic; and (b) photograph

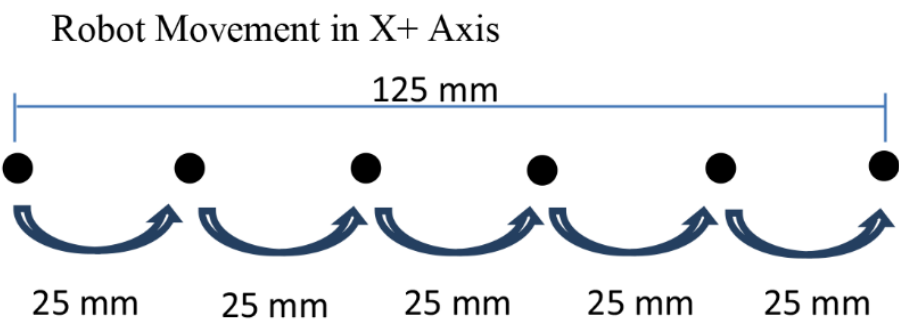

Figure 2 Robot movement measured in the $\mathrm{X}+$ direction

Figure 2 shows the path of the movement that will be covered by the robot over a distance of $125 \mathrm{~mm}$. Each $25 \mathrm{~mm}$ movement of the robot was stopped for 5 seconds to give time to measure the coordinate using PCMM. Each trial was performed eight times, with the cycle consisting of four cycles in the $\mathrm{X}+$ direction and four in the $\mathrm{X}$ - direction, and with the results consisting of 40 set of data, as was the case for the $\mathrm{Y}+$ and $\mathrm{Y}$ - direction (Figure 1a). The trial was performed with a variable rate of 2 and $2.5 \mathrm{~mm} / \mathrm{s}$. In addition, measurement of the stepper motor response to the robot movements was also made by entering the delay value (in microseconds) into a microcontroller and setting the movement on the $\mathrm{X}$ and $\mathrm{Y}$ axes at $25 \mathrm{~mm}$. The delay value had been determined and entered into the microcontroller so that the stepper motor could move within a certain distance and time. Subsequently, the stepper motor was run, and a stopwatch and PCMM were used during this process to determine the time (seconds) needed for the stepper motor to reach a movement of $25 \mathrm{~mm}$ from each of the delay values (microseconds) (Jovanovski, 2018).

$$
V_{x}=\frac{X(m m)}{t(\min )}, V_{y}=\frac{Y(m m)}{t(\min )}
$$


All of the data from the trial were processed by the control chart method to establish the capabilities of each axis in performing the repetitive movement (repeatability). After the processing was complete, the process was continued in order to compare the actual movement measured with the theoretical movement and to determine the accuracy of the robot.

\section{RESULTS AND DISCUSSION}

\subsection{Characteristics of the Stepper Motor}

From the results of the tests performed using PCMM, it was found that the stepper motor on the $\mathrm{X}$ and $\mathrm{Y}$ axes had the following speed characteristic. Figure 3 shows the characteristics when using the stepper motor in micro-step mode; the graph shows the nonlinearity of the motor while receiving a pulse from a microcontroller. This happens because in micro-step mode the motor will receive the pulses divided into hundreds of signals to make the movement of the motor more refined. The negative effect of this mode was a reduction in the amount of torque of the motor by $30 \%$ and its inability to perform the desired movement with the high-speed signals given (Scarpino, 2015).

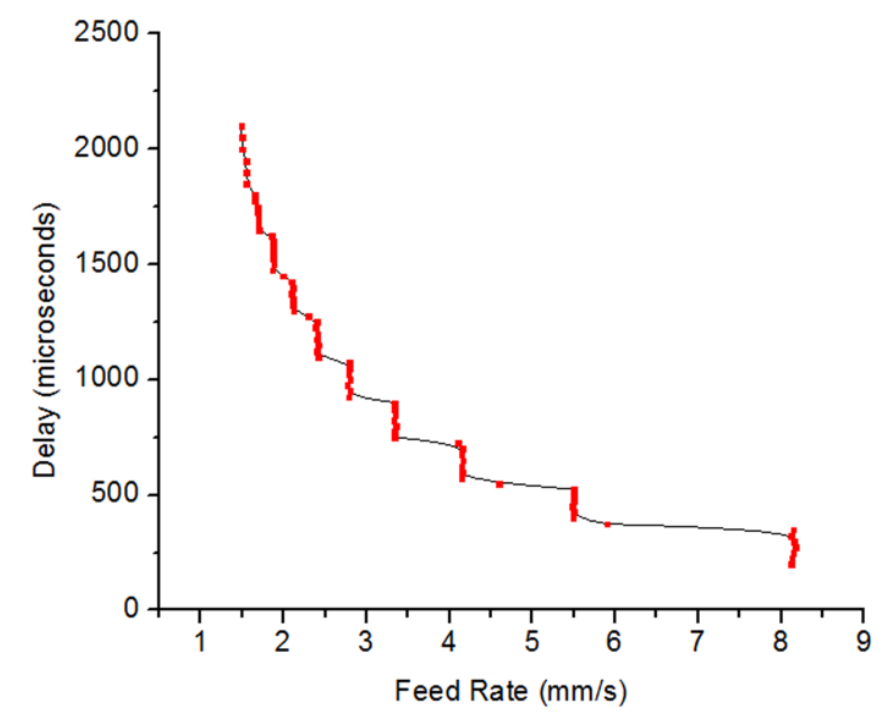

Figure 3 Relationship between feed rate and delay in transmitted pulse

\subsection{Movement on the $\mathrm{X}$ Axis}

Figure 4a shows a graph of the moving average control chart in the $\mathrm{X}$ axis direction $\mathrm{X}+$ that did not move out of the upper and lower control limits. From the graph, it can be concluded that the movement of the robot with 5 degrees of freedom (DOF) had a good degree of repeatability at a speed of $2 \mathrm{~mm} / \mathrm{s}$; this is proven because when taking as many of 20 data in four cycles in the $\mathrm{X}+$ direction, the average value of each movement does not deviate from the limits on the control chart. However, although it does not deviate from the robot control chart, it displays an error in achieving the desired accuracy. The control limit values in this case amounted to 24.16 $\mathrm{mm}$, compared to the actual desired distance of $25 \mathrm{~mm}$. Therefore, there was an error of $3.3 \%$ from the desired distance. This error came from the difference between the computer input and actual movement of the stepper motor. When the computer command the movement with the speed of $2 \mathrm{~mm} / \mathrm{s}$, the motor will move the robot in $12.5 \mathrm{~s}$. But in fact, the motor moves at a speed of $1.93 \mathrm{~mm} / \mathrm{s}$, so it produces a spacing of $24.16 \mathrm{~mm}$. Based on the distribution of each point, it can be seen that the average of the distribution of each point was $\pm 0.05 \mathrm{~mm}$, which was also linked to the error of the measurement tools of $0.02 \mathrm{~mm}$. 


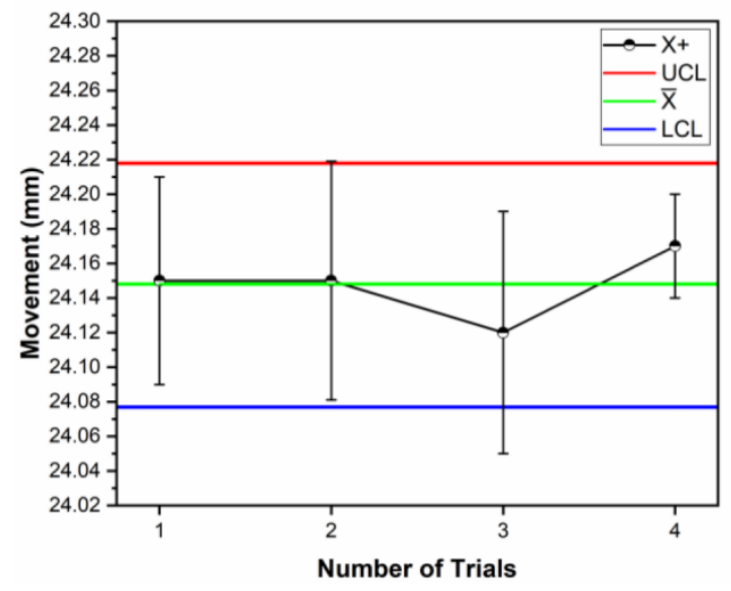

(a)

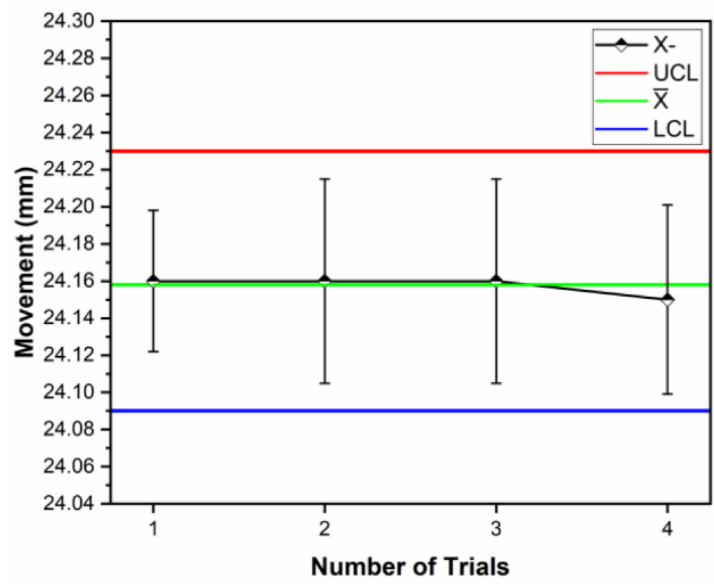

(b)

Figure 4 Average movement at feed rate speed of $2 \mathrm{~mm} / \mathrm{s}$ on the $\mathrm{X}$ axis: (a) $\mathrm{X}+$; and (b) $\mathrm{X}$ -

Figure $4 \mathrm{~b}$ shows the control chart of the average movement in the $\mathrm{X}$ axis direction $\mathrm{X}-$ - These data were taken from the repetition of four cycles of movement of the robot in the X-direction, so a total of 20 sets of data can be determined. It can be seen in the graph that no points were beyond the upper limit (UCL) or lower limit (LCL), and it has a control value limit of 24.16 $\mathrm{mm}$. Compared with the data in Figure 4a, it appears that the X-direction stepper motors achieve better outcomes, with an average of three points, which equal the control limit. The Xdirection have the same level of accuracy as the movement in the $\mathrm{X}+$ direction that of 24.16 $\mathrm{mm}$, which means the error of accuracy was $3.3 \%$, with a standard deviation of $\pm 0.05 \mathrm{~mm}$.

Table 1 shows the results of the trials that were completed at five different speeds in the $\mathrm{X}$ axis. It is shown that the variance of the data with the smallest standard deviation reached by the motor at speeds of 3 and $4 \mathrm{~mm} / \mathrm{s}$ is $\pm 0.04 \mathrm{~mm}$. However, the best accuracy of $0.83 \%$ was achieved at a speed of $2.5 \mathrm{~mm} / \mathrm{s}$, even though the amount of variation obtained had a value of $\pm 0.06 \mathrm{~mm}$. The differences in the variation of the overall data obtained in the experiment out of the total of five speed variations indicate that the average ability of robots to cover the distance had a level of repeatability of $0.096 \mathrm{~mm}(96 \mu \mathrm{m})$.

Table 1 Influence of the speed of motor movement on accuracy and repeatability on the $\mathrm{X}$ axis

\begin{tabular}{cccc}
\hline $\begin{array}{c}\text { Feed Rate } \\
(\mathrm{mm} / \mathrm{s})\end{array}$ & $\begin{array}{c}\text { Standard Deviation } \\
(\mathrm{mm})\end{array}$ & $\begin{array}{c}\text { Accuracy } \\
(\%)\end{array}$ & $\begin{array}{c}\text { Repeatability } \\
(\mathrm{mm})\end{array}$ \\
\hline 2.0 & 0.05 & 96.610 & 0.100 \\
2.5 & 0.06 & 99.178 & 0.120 \\
3.0 & 0.04 & 95.850 & 0.080 \\
3.5 & 0.05 & 98.160 & 0.100 \\
4.0 & 0.04 & 91.610 & 0.080 \\
\hline \multicolumn{3}{c}{} & 0.096 \\
\hline
\end{tabular}

\subsection{Movement on the Y Axis}

Figure 5a illustrates the average of the five movements for the four experiment cycles. It can be seen that in the four cycles no point approached the upper or lower limits as they all had an average value equal to the control limit. However, at all the points there was a large deviation in the differences; at the first point, or first experiment, there was significant deviation showing the variation in the data which fitted inside the detection limits. The difference between UCL and LCL was as high as $0.08 \mathrm{~mm}$, although the variation data did not exceed this limit, and 
remained within the limits. In this condition, the $\mathrm{Y}$ axis still showed good repeatability in executing the movement up to $25 \mathrm{~mm}$. Based on the level of accuracy in this case, on the $\mathrm{Y}$ axis deviation was found to be $0.43 \mathrm{~mm}$, so the value of the error was $1.8 \%$. The magnitude of the errors that occurred may have been caused by the loss of stepping pulses given to the stepper motor in a matter of microseconds, which affected the level of closeness to the actual distance travelled by the motor with the theoretical distance calculated by the computer. The computers made the calculations correctly, but when calculating the conversion speed, errors occurred because of the actual ability of the motor, which did not match the computer calculations.

Figure $5 \mathrm{~b}$ shows a graph of the data retrieval of the five unidirectional movements performed by the four cycles on the $\mathrm{Y}$ axis in the $\mathrm{Y}$ - direction at a distance of $25 \mathrm{~mm}$. The graph shows that the average of each movement remained close to the control limit of $24.5 \mathrm{~mm}$. However, in the second set of data there were deviations at a level of $\pm 0.04 \mathrm{~mm}$. This means that in the second experiment the lowest data values were the same as in the lower limit value control chart. Such irregularities were still within the limits of the charts. If the value chart on the Y-is compared with the value chart on the $\mathrm{Y}+$, it can be seen that there is differences in the control limit value of $0.07 \mathrm{~mm}$. It is shown that at low velocity movement on the both $\mathrm{Y}+$ and $\mathrm{Y}$ - axis produces the higher backlash compared to the movement along $\mathrm{X}$ axis.

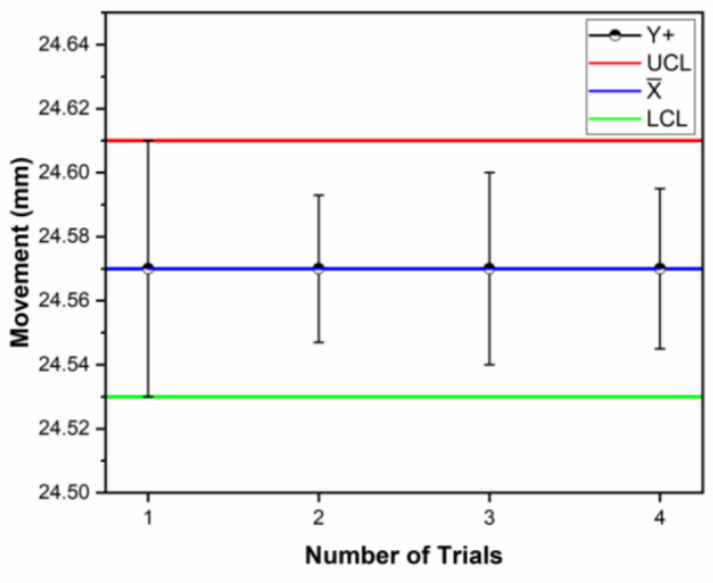

(a)

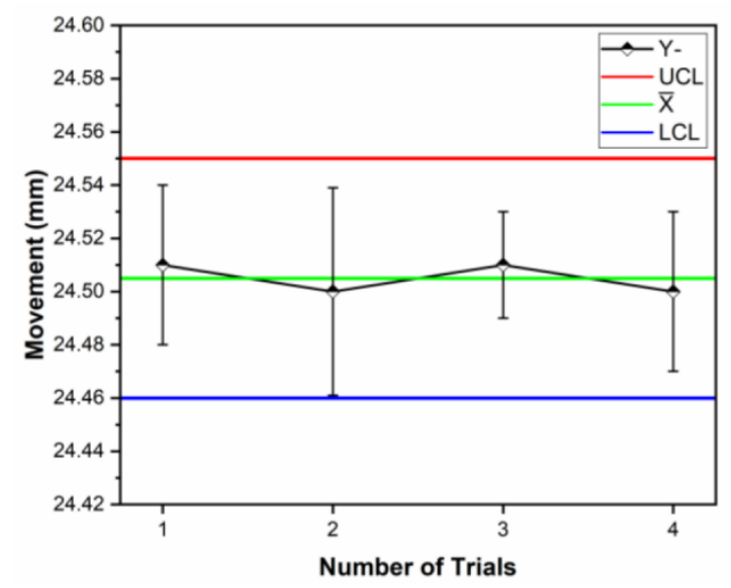

(b)

Figure 5 Average movement at feed rate speed of $2 \mathrm{~mm} / \mathrm{s}$ on the $\mathrm{Y}$ axis: (a) $\mathrm{Y}+$; and (b) $\mathrm{Y}$ -

Table 2 Influence of speed of motor movement on accuracy and repeatability on the $\mathrm{Y}$ axis

\begin{tabular}{cccc}
\hline $\begin{array}{c}\text { Feed Rate } \\
(\mathrm{mm} / \mathrm{s})\end{array}$ & $\begin{array}{c}\text { Standard Deviation } \\
(\mathrm{mm})\end{array}$ & $\begin{array}{c}\text { Accuracy } \\
(\%)\end{array}$ & $\begin{array}{c}\text { Repeatability } \\
(\mathrm{mm})\end{array}$ \\
\hline 2.0 & 0.04 & 96.61 & 0.080 \\
2.5 & 0.03 & 99.17 & 0.060 \\
3.0 & 0.05 & 95.85 & 0.100 \\
3.5 & 0.07 & 98.16 & 0.140 \\
4.0 & 0.08 & 91.61 & 0.160 \\
\hline \multicolumn{3}{c}{} & 0.108 \\
\hline
\end{tabular}

Table 2 shows the results of the testing that was conducted on the five speed characteristics on the $\mathrm{Y}$ axis. It can be seen that variations in the data with the lowest deviation values were achieved at a speed of $2.5 \mathrm{~mm} / \mathrm{s}$ is $\pm 0.03 \mathrm{~mm}$. The best accuracy was also shown at a speed of $2.5 \mathrm{~mm} / \mathrm{s}$, with a speed error value of the target range of $0.83 \%$. The differences in the variation of the overall data obtained in the experiment with the five speed variations indicate that the average ability of the robot in executing the distance had a level of repeatability of $0.108 \mathrm{~mm}$ 
$(108 \mu \mathrm{m})$. Accuracy and repeatability are important features of a robot, especially if it is used as a measurement system (Nubiola \& Bonev, 2013). Zaeh et al. (2010) indicate that the value of repeatability rates in robots in an industry is less than $150 \mu \mathrm{m}$.

\subsection{Movement on $X$ and $Y$ Axes}

Figure 6 shows the results of the 2-axis movement between the $\mathrm{X}$ and $\mathrm{Y}$ axes, with feed rate speeds of 2 and $2.5 \mathrm{~mm} / \mathrm{s}$, to obtain a hexagonal shape with dimensions of $25 \mathrm{~mm}$. It can be seen that the 2-axis movement at those parameters produces an error value in the of range 0-1 $\mathrm{mm}$. This error occurred because of the conversion factor resulted from movement calculation at a computer and the magnitude of signal speed that sent to the robot.

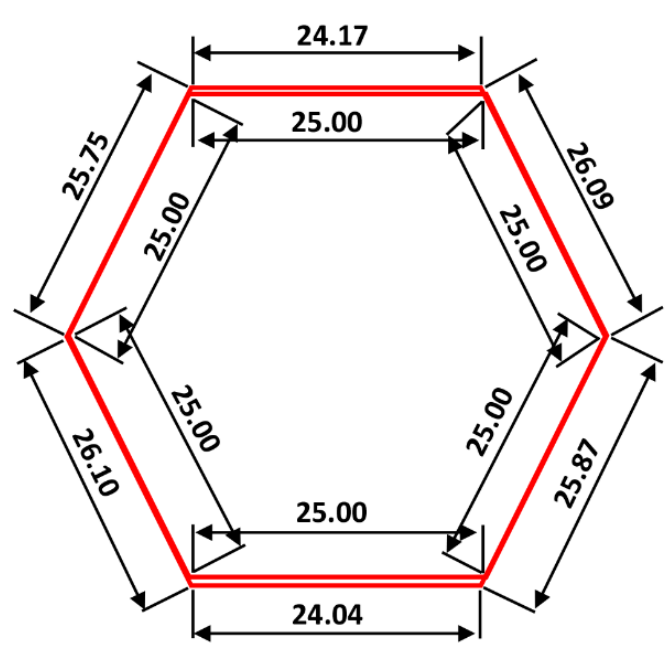

(a)

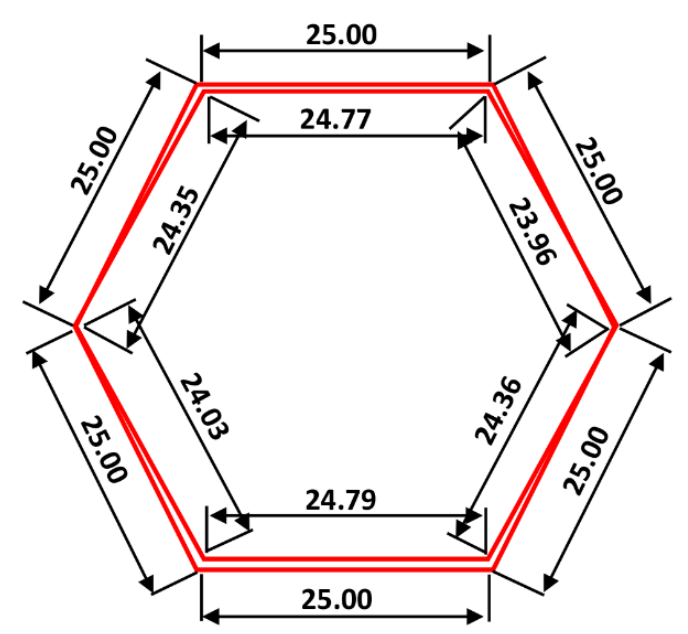

(b)

Figure 6 Results of 2-axis movement between the $\mathrm{X}$ and $\mathrm{Y}$ axes to make a hexagonal profile with dimensions of $25 \mathrm{~mm}$

\subsection{Robot Applications}

The gantry robot system is suitable for spot welding such as FSW. This is because FSW requires a strong robot frame to withstand vibrations during the welding process. In addition, the level of accuracy and repeatability of robots is also another consideration. The feed rate used on this robot was $2.5 \mathrm{~mm} / \mathrm{s}$ for the best level of accuracy, while its repeatability rate on the $\mathrm{X}$ and $\mathrm{Y}$ axes was lower than $150 \mu \mathrm{m}$. Therefore, this preliminary study using 2-axis movement shows that the robot can be employed to make a honeycomb structure with spot welding (Cohal, 2017).

\section{CONCLUSION}

In this paper, a gantry robot system has been successfully developed for robotic FSW applications. This preliminary research has focused on the 2D axis movement of the gantry robot to determine its level of accuracy and repeatability. Measurement of X and Y axes was made to evaluate the ability of the gantry robot with several variations in feed rate. The results show that the best level of accuracy was $0.83 \%$ at a velocity of $2.5 \mathrm{~mm} / \mathrm{s}$, while the repeatability rate produced on the $\mathrm{X}$ and $\mathrm{Y}$ axis was $96 \mu \mathrm{m}$ and $108 \mu \mathrm{m}$, respectively. Future work will focus on the remaining three axes and the application of the gantry robot for FSW welding, and will also examine the 3 -axis movements that have not been discussed in this paper, and their application in welding. 


\section{ACKNOWLEDGEMENT}

The author would like to express his sincere gratitude for the financial support of the Directorate Research and Public Service, Universitas Indonesia, through contract number 1753/UN2.R12/PPM.00.00/2016, with the title of "Pengembangan Mesin Tungsten Inert Gas Welding Otomatis Berbasis Machine Vision dan Neural Network".

\section{REFERENCES}

Baicu, C.F., Rahn, C.D., Dawson, D.M., 1998. Backstepping Boundary Control of Flexible-link Electrically Driven Gantry Robots. IEEE/ASME Transactions on Mechatronics, Volume 3(1), pp. 60-66

Baskoro, A.S., Habibullah, M.D., Arvay, Z., Kiswanto, G., Chen, Z., 2015. Effects of DwellTime and Plunge Speed during Micro Friction Stir Spot Welding on Mechanical Properties of Thin Aluminum A1100 Welds. Applied Mechanics and Materials, Volume 758, pp 29-34

Baskoro, A.S., Muzakki, H., Kiswanto, G., Winarto., 2017. Effects of Micro Resistance Spot Welding Parameters on the Quality of Weld Joints on Aluminum Thin Plate AA 1100. International Journal of Technology, Volume 8(7), pp 1306-1313

Cohal, V., 2017. Spot Welding of Honeycomb Structures. In: IOP Conference Series: Materials Science and Engineering, Volume 227

Guillo, M., Dubourg, M., 2016. Impact \& Improvement of Tool Deviation in Friction Stir Welding: Weld Quality \& Real-time Compensation on an Industrial Robot. Robotics and Computer-Integrated Manufacturing, Volume 39, pp. 22-31

Ji-Hyoung, L., Jae-Kwon, K., Hyung-Shik, K., In-Wan, P., 2001. Development of Multi-axis Gantry Type Welding Robot System using a PC-based Controller. In: The 2001 IEEE International Symposium on Industrial Electronics Proceedings, 12-16 June 2001, Pusan, South Korea, pp. 1536-1541

Jovanovski, N., Kjosev, J., 2018. Synchronized Control of Four or More Stepper Motors for Computer Numerical Controled Machines and 3D Printers. In: Proceedings of the 6th International Conference on Applied Innovations in IT (ICAIIT), 13 March 2018, Koethen, Germany, pp. 45-50

Kah, P., Shrestha, M., Hiltunen, E., Martikainen, J., 2015. Robotic Arc Welding Sensors and Programming in Industrial Applications. International Journal of Mechanical and Materials Engineering, Volume 10(13), pp. 1-16

Mendes, N., Neto, P., Simão, M.A., Loureiro, A., Pires, J.N., 2016. A Novel Friction Stir Welding Robotic Platform: Welding Polymeric Materials. The International Journal of Advanced Manufacturing Technology, Volume 85(1-4), pp. 37-46

Meressi, T., 1998. Modeling and Control of a Three Dimensional Gantry Robot. In: Proceedings of the $37^{\text {th }}$ IEEE Conference on Decision and Control, 18 December 1998, Tampa, USA, pp. 1514-1515

Muzakki, H., Baskoro, A.S., Kiswanto, G., Winarto, W., 2018. Mechanical Properties of the Micro Resistance Spot Welding of Aluminum Alloy to Stainless Steel with a Zinc Interlayer. International Journal of Technology, Volume 9(4), pp. 686-694

Nubiola, A., Bonev, I.A., 2013. Absolute Calibration of an ABB IRB 1600 Robot using a Laser Tracker. Robotics and Computer-Integrated Manufacturing, Volume 29(1), pp. 236-245

Samhouri, M., Raoufi, A., Surgenor, B., 2005. Control of a Pneumatic Gantry Robot for Grinding: a Neuro-fuzzy Approach to PID Tuning. In: Proceedings of the 2005 IEEE Conference on Control Applications, 28-31 August 2005, Toronto, Ont., Canada, pp. $452-458$ 
Scarpino, M., 2015. Motors for Makers: A Guide to Steppers, Servos, and Other Electrical Machines. Indiana: Que Publishing

Smith, C.B., 2004. Robotic Friction Stir Welding using a Standard Industrial Robot. Kei Kinzoku Yosetsu (Journal of Light Metal Welding and Construction), Volume 42(3), pp. 40-41

Soron, M., Kalaykov, I., 2006. A Robot Prototype for Friction Stir Welding. In: Proceedings of the 2006 IEEE Conference on Robotics, Automation and Mechatronics, 1-3 June 2006, Bangkok, Thailand

Voellner, G., Zaeh, M., Silvanus, J., 2008. Influence of Machine Types on FSW Seam Qualities. In: Proceedings of the $7^{\text {th }}$ International Friction Stir Welding Symposium, 20-22 May 2008, Awaji Island, Japan

Von Strombeck, A., Schilling, C., Dos Santos, J.F., 2001. Robotic Friction Stir Welding- Tool, Technology and Applications. Biuletyn Instytutu Spawalnictwa (Poland), Volume 45(6), pp. 49-52

Zaeh, M.F., Hatwig, J., Musiol, J., Roesch, O., Reinhart, G., 2010. Analysis of the Accuracy of Industrial Robots and Laser Scanners for Remote Laser Beamwelding and Cutting. In: Proceedings of the ISR 2010 (41 ${ }^{\text {st }}$ International Symposium on Robotics) and ROBOTIK 2010 ( $6^{\text {th }}$ German Conference on Robotics), 7-9 June, 2010, Munich, Germany 